\title{
Effects of oral and inhaled salbutamol and oral pirbuterol on right and left ventricular function in chronic bronchitis
}

\author{
R J D WINTER, J A LANGFORD, R M RUDD
}

\begin{abstract}
In many patients with chronic bronchitis and emphysema right and left ventricular ejection fractions (RVEF and LVEF) are reduced. A study was conducted using multiple gated equilibrium radionuclide ventriculography to compare the effects of oral salbutamol $4 \mathrm{mg}$ and pirbuterol $15 \mathrm{mg}$ on cardiac function in 12 patients with chronic bronchitis (forced expiratory volume in one second 0.86 (SEM 0.12) 1; arterial oxygen pressure 8.2 (SEM 0.5) $\mathrm{kPa}(61.7$ (SEM 3.8) $\mathrm{mm} \mathrm{Hg}$ )). Different doses of nebulised salbutamol $(500 \mu \mathrm{g}$ and $5 \mathrm{mg}$ ) were also compared in nine of the patients. Both oral salbutamol and oral pirbuterol produced significant increases in RVEF and LVEF at 60 and 90 minutes after drug ingestion ( $p<0.01$ in each case). There were no significant differences between salbutamol and pirbuterol in their effects on RVEF and LVEF. Inhaled salbutamol at doses commonly prescribed had no significant effect on RVEF and LVEF after 20 and 60 minutes.

Salbutamol and pirbuterol given by mouth have similar actions on RVEF and LVEF. Further studies are necessary to assess the effects of long term $B_{2}$ agonists in this group of patients.
\end{abstract}

\section{Introduction}

Clinical evidence of right ventricular failure is associated with a poor prognosis in patients with chronic bronchitis, and the five year survival rate is frequently quoted as only $30 \% .^{1}$ Such vascular resistance and an improvement in cardiac index..$^{5}$, There is little information about the effect of salbutamol on cardiac function in patients with chronic bronchitis and emphysema. We have compared the effects of oral salbutamol and oral pirbuterol and have also studied the effect of inhaled salbutamol on RVEF and LVEF in these patients.

\section{Methods}

We studied 12 patients with severe airflow limitation due to chronic bronchitis and emphysema (mean forced expiratory volume in one second 0.86 (SEM 0.12$) 1$; arterial oxygen pressure 8.2 (SEM 0.5$) \mathrm{kPa}$ (61.7 (SEM 3.8) $\mathrm{mm} \mathrm{Hg}$ ); arterial carbon dioxide pressure 5.3 (SEM 0.4) $\mathrm{kPa}(40.2(\mathrm{SEM} \mathrm{3.0)} \mathrm{mm} \mathrm{Hg})$ ). All patients gave informed consent at the time of the study, which was approved by the hospital's ethics committee.

RVEF and LVEF were measured by multiple gated radionuclide ventriculography. ${ }^{8}$ This technique uses an in vivo method of labelling red cells. Amerscan stannous agent $0.03 \mathrm{ml} / \mathrm{kg}$ is injected intravenously, and 30 minutes later $20 \mathrm{mCi}{ }^{99}$ technetium pertechnetate is injected into a peripheral vein. After five minutes to allow equilibration in the blood pool the multiple gated study is performed using a Siemens large field gammacamera and Medical Data Systems computer. The patient lies supine with the camera angled $10^{\circ}$ caudally and roughly $30^{\circ}$ left anterior oblique; in each patient the angle is adjusted to obtain maximum separation of the ventricles. Analysis of two right ventricular regions of interest is performed to calculate RVEF. Fourier phase and amplitude functional images are used to help trace the regions of interest. All studies were analysed by the same observer (JAL).

Patients were randomised to receive either $15 \mathrm{mg}$ pirbuterol or $4 \mathrm{mg}$ salbutamol by mouth on each of two days in a double blind crossover manner. These doses reportedly have equal peak broncho-

TABLE I-Effects of oral salbutamol and pirbuterol on right and left ventricular ejection fractions (RVEF and LVEF). Values are means (SEM in parentheses)

\begin{tabular}{|c|c|c|c|c|c|c|}
\hline & \multicolumn{3}{|c|}{ RVEF } & \multicolumn{3}{|c|}{ LVEF } \\
\hline & \multirow{2}{*}{ Control } & \multicolumn{2}{|c|}{ Minutes after drug } & \multirow{2}{*}{ Control } & \multicolumn{2}{|c|}{ Minutes after drug } \\
\hline & & 60 & 90 & & 60 & 90 \\
\hline $\begin{array}{l}\text { Salbutamol } 4 \mathrm{mg} \\
\text { Pirbuterol } 15 \mathrm{mg}\end{array}$ & $\begin{array}{l}0.32(0.02) \\
0.31(0.03)\end{array}$ & $\begin{array}{l}0.39(0.03)^{* *} \\
0.37(0.03)^{* *}\end{array}$ & $\begin{array}{l}0.36(0.03)^{*} \\
0.36(0.03)\end{array}$ & $\begin{array}{l}0.53(0.03) \\
0.54(0.04)\end{array}$ & $\begin{array}{l}0.60(0.04)^{* *} \\
0.62(0.04)^{* *}\end{array}$ & $\begin{array}{l}0.59(0.04)^{*} \\
0.61(0.04)^{*}\end{array}$ \\
\hline
\end{tabular}

patients have reduced right and left ventricular ejection fractions (RVEF and LVEF). ${ }^{2}$ Pirbuterol, a selective $\beta_{2}$ adrenergic agonist, has recently been shown to produce an increase in RVEF accompanied by a reduction in mean pulmonary artery pressure and an increase in cardiac output in this group of patients. $^{3} 4$ In chronic heart failure due to coronary artery disease both salbutamol and pirbuterol produce a fall in systemic

London Chest Hospital, London E2 9JX

R J D WINTER, MB, MRCP, registrar in thoracic medicine

J A LANGFORD, DCR(R), DNM, nuclear medicine radiographer

R M RUDD, MD, MRCP, consultant physician

Correspondence to: Dr R M Rudd. dilator effect.9 Sympathomimetic drugs and theophyllines were not taken for 12 hours before the study. RVEF and LVEF were measured before and 60 and 90 minutes after drug ingestion.

Two doses of nebulised salbutamol were studied sequentially in a separate study. The doses of $500 \mu \mathrm{g}$ and $5 \mathrm{mg}$ were made up in $4 \mathrm{ml}$ saline and given by a Minineb nebuliser. A sequential design enabled RVEF and LVEF to be obtained for both doses of inhaled salbutamol with a single gated blood pool study.

Results are stated as mean values and standard errors of the mean (SEM). Statistical evaluation was by Student's $t$ test.

\section{Results}

Table I gives the mean values for RVEF and LVEF before and after drug ingestion. Both salbutamol and pirbuterol produced significant increases in RVEF and LVEF after 60 and 90 minutes 
$(p<0.01$ in each case). There were no significant differences between salbutamol and pirbuterol in their effects on RVEF and LVEF. The increments produced by each drug were not related to the initial ejection fractions (Tukey's corner test for monotonic association $\left.{ }^{10}\right)$. Mean heart rate increased from 67 (SEM 2)/min at rest to 86 (3) and $85(2) / \mathrm{min}$ at 60 and 90 minutes after oral salbutamol. After pirbuterol there was an increase from $75(4) / \mathrm{min}$ to $92(4)$ and $84(4) /$ $\mathrm{min}$ at 60 and 90 minutes respectively. There was no significant difference between the drugs in the increases in heart rate produced. variable response to the larger dose may reflect variable absorption of the drug by this route.

It has been suggested that because pirbuterol has appreciable inotropic action and vasodilator properties it may improve cardiac function to a greater extent than other $\beta_{2}$ agonists. ${ }^{11} \mathrm{At}$ doses that produce equal peak bronchodilatation we found no difference between pirbuterol and salbutamol in their effects on RVEF and LVEF in patients with chronic hypoxia due to chronic bronchitis and emphysema. The increase in RVEF may

TABLE $1 \mathrm{I}-$ Effects of inhaled salbutamol on right and left ventricular ejection fractions (RVEF and LVEF). Values are means (SEM in parentheses)

\begin{tabular}{|c|c|c|c|c|c|c|}
\hline & \multicolumn{3}{|c|}{ RVEF } & \multicolumn{3}{|c|}{ LVEF } \\
\hline & \multirow{2}{*}{ Control } & \multicolumn{2}{|c|}{ Minutes after drug } & \multirow{2}{*}{ Control } & \multicolumn{2}{|c|}{ Minutes after drug } \\
\hline & & 20 & 60 & & 20 & 60 \\
\hline $\begin{array}{l}\text { Salbutamol } 500 \mu \mathrm{g} \\
\text { Salbutamol } 5 \mathrm{mg}\end{array}$ & $\begin{array}{l}0.33(0.03) \\
0.32(0.03)\end{array}$ & $\begin{array}{l}0.32(0.03) \dagger \\
0.33(0.03) \dagger\end{array}$ & $\begin{array}{l}0.33(0.03) \dagger \\
0.34(0.03) \dagger\end{array}$ & $\begin{array}{l}0.51(0.05) \\
0.51(0.05)\end{array}$ & $\begin{array}{l}0.51(0.05) \dagger \\
0.54(0.05) \dagger\end{array}$ & $\begin{array}{l}0.52(0.05) \dagger \\
0.56(0.05) \dagger\end{array}$ \\
\hline
\end{tabular}

Table II shows the effects of inhaled salbutamol on RVEF and LVEF. Overall there was no significant effect with either $500 \mu \mathrm{g}$ or $5 \mathrm{mg}$. Nevertheless, the response to $5 \mathrm{mg}$ was variable and there was a trend towards an increase in LVEF, though not in RVEF.

The mean differences between repeated measurements on two occasions for RVEF and LVEF were 0.03 (SEM 0.01) and 0.04 $(0.01)$ respectively. The mean differences between two assessments on different occasions by the same observer of the same equilibrium study were $0.02(0.003)$ and $0.01(0.003)$ for RVEF and LVEF respectively.

\section{Discussion}

Our patients with chronic bronchitis and emphysema with severe airflow limitation had reduced RVEF and LVEF at rest. Similar findings were reported by Macnee and colleagues, who found that RVEF was correlated with arterial oxygen concentration and inversely correlated with carbon dioxide tension. ${ }^{2}$ We find, like Xue and colleagues, ${ }^{8}$ that while RVEF varies considerably in chronic bronchitis, reproducible results are obtained on repeated assessment of individual patients, permitting evaluation of acute therapeutic regimens.

In cardiac failure due to coronary artery disease oral pirbuterol and salbutamol increase cardiac output. The dominant mechanism is a reduction in systemic vascular resistance rather than a direct inotropic effect. ${ }^{5-7}$ Our results show a similar improvement in left heart performance in chronic bronchitis after oral $\beta_{2}$ agonists.

Other studies with invasive techniques have shown a fall in pulmonary artery pressure after oral pirbuterol in patients with chronic bronchitis ${ }^{4}$ and after oral salbutamol in patients with coronary artery disease. ${ }^{6}$ Probably the improvement in RVEF seen is mediated mainly by a fall in pulmonary artery pressure and a reduction in pulmonary vascular resistance. We found that both oral salbutamol and pirbuterol produced similar increases in RVEF in patients with chronic bronchitis.

In most patients inhaled salbutamol at doses commonly prescribed produced no effect on RVEF and LVEF. The not be beneficial because it may be accompanied by redistribution of pulmonary perfusion, which may adversely affect arterial oxygen saturation. ${ }^{3}$ Further studies are necessary to assess the effects of long term $\beta_{2}$ agonists in this group of patients.

We thank Allen and Hanburys Ltd and Pfizer (UK) Ltd for their help with this study.

\section{References}

${ }^{1}$ Middleton HC, Peake MD, Howard P. Hypoxaemia in chronic bronchitis. Thorax 1979;34:313-6.

${ }^{2}$ Macnee W, Xue QF, Hannan WJ, Flenley DC, Adie CJ, Muir AL. Assessment by radionuclide angiography of right and left ventricular function in chronic bronchitis and emphysema. Thorax 1983;38: 494-500.

${ }^{3}$ Peacock A, Busst C, Dawkins K, Denison DM. Response of pulmonary circulation to oral pirbuterol in chronic airflow obstruction. $\mathrm{Br} \mathrm{Med} \mathcal{F}$ $1983 ; 287: 1178-80$.

4 Macnee W, Wathen CG, Hannan WJ, Flenley DC, Muir AL. Effects of pirbuterol and sodium nitroprusside on pulmonary haemodynamics in hypoxic cor pulmonale. $\mathrm{Br}$ Med F 1983;287:1169-72.

${ }^{5}$ Timmis AD, Strak SK, Chamberlain DA. Haemodynamic effects of salbutamol in patients with acute myocardial infarction. $\mathrm{Br}$ Med $\mathcal{F}$ 1979;ii:1101-3.

6 Bourdillon PDV, Dawson JR, Foale RA, Timmis AD, Poole-Wilson PA, Sutton CG. Salbutamol in treatment of heart failure. Br Heart f 1980; $43: 206-10$.

7 Dawson JR, Canepa Anson R, Kuan P, et al. Treatment of chronic heart failure with pirbuterol; acute haemodynamic responses. $\mathrm{Br}$ Med $\mathcal{J}$ $1981 ; 282: 1423-6$.

${ }^{8}$ Xue QF, Macnee W, Flenley DC, Hannan WJ, Adie CJ, Muir AL. Can right ventricular performance be assessed by equilibrium radionuclide ventriculography ? Thorax 1983;38:486-93.

${ }^{9}$ Pitts NE, Borger AP, Ghaly MS, Salsbury DS, Gans DJ. Pirbuterol: a new selective beta-agonist. In: Richardson RG, ed. Royal Society of Medicine international congress and symposium series. No 56 . London: RSM, 1983.

${ }^{10}$ Quenouille $\mathrm{MH}$, ed. Rapid statistical calculations. 2nd ed. London: Griffin, 1972:31.

${ }^{11}$ Howard P. Drugs or oxygen for hypoxic cor pulmonale? Br Med $\mathcal{F} 1983$; 287:1159-60.

(Accepted 4 Fanuary 1984) 